Review

\title{
Recent Developments in Detoxification of Organic Pollutants Using CdS-based Nanocomposites
}

\author{
Sanya Mishra, Ravi Mani Tripathi ${ }^{\smile}$, Om Prakash Sinha \\ Amity Institute of Nanotechnology, Amity University Uttar Pradesh, Sector 125, Noida, 201303, India.
}

들 Corrponding author. E-mail: rmtripathi@amity.edu,rmtripathi02@gmail.com

Received: Oct. 8, 2020; Accepted: Feb. 19, 2021; Published: Apr. 7, 2021

Citation: Sanya Mishra, Ravi Mani Tripathi, and Om Prakash Sinha,Recent Developments in Detoxification of Organic Pollutants Using CdS-based Nanocomposites. Nano Biomed. Eng., 202I, I3(2): 95-I08.

DOI: 10.5101/nbe.v13i2.p95-108.

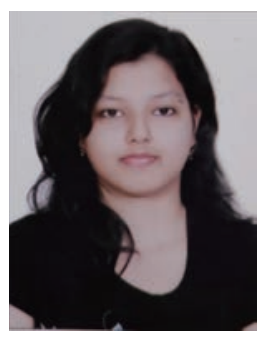

Ms. Sanya Mishra is currently pursuing her B. Tech + M. Tech (int) in Nanotechnology from Amity Institute of Nanotechnology, Amity University Uttar Pradesh, Noida, Uttar Pradesh, India.

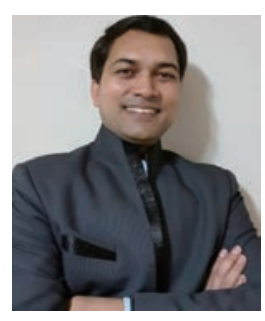

Dr. Ravi Mani Tripathi is working as Assistant Professor (Senior grade) at Amity Institute of Nanotechnology, Amity University Uttar Pradesh, Noida, India. Dr Ravi received his Ph. D in Nanobiotechnology from Jiwaji University, Gwalior, India. He did his post-doctoral research at School of Pharmacy, Sungkyunkwan University, South Korea. He received young scientist award in 2019 by International Scientist award on Engineering, Science, and Medicine. He has 14 years of teaching and research experience in the area of Nanobiotechnology. He developed innovative method for the biological synthesis of nanomaterials like particles, nanodots, flowers, rods, fibers, etc. He has gained expertise in the area of antimicrobial nanomedicine, colorimetric detection and catalytic/photocatalytic degradation of toxic pollutants. He got recognition as reviewer of highly reputed journals likes Sensors and Actuators B, Scientific Reports, Materials Letter, IOP Nanotechnology, Journal of Photochemistry \& Photobiology B, IET Nanobiotechnology, etc. He has authored more than 35 high quality research and review articles in peerreviewed journals of international repute.

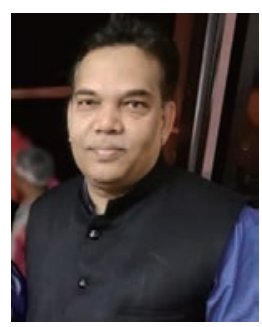

Dr. Om Prakash Sinha was born on $16^{\text {th }}$ Jan. 1972 and did his Ph.D. in Physics from Banaras Hindu University, Varanasi in 2001. He joined as Post-Doctoral fellow at Inter University Centre for Department of Atomic Energy Facility, Indore, India (2002-2003) and Institute of Physics, Bhubaneswar, India (2003-2004). Later, he joined ICFAI University Dehradun, India (2004-2005) followed by Amity University, UP, Noida, India. (2005-onwards). Presently, he has been working as a Professor and Director at Amity Institute of Nanotechnology, Amity University Uttar Pradesh, Noida, India. During his association at Amity, he has been recipient of Marie Curie Fellowship at Institute of Physics, Jagiellonian University, Krakow, Poland (20072008), Guest Scientist at Institute of Ion Beam, Helmholtz-Zentrum Dresden-Rossendorf, Dresden, Germany (2009) and Senior Post Doctoral Researcher at ASTRaL, Lappeenranta University of Technology, Mikkeli, Finland (2009). His areas of interest are Semiconductor nanostructures, 2D materials, Organic Electronics and photocatalytic properties of materials. He has handled various R \& D projects. Prof Sinha has around $70 \mathrm{SCI}$ publications to his credits and more than 150 research papers in Conferences. He has delivered more than 60 invited talks and are member of several peer review team of different publishers across the world. He is editorial team member of Frontiers in Materials(Thin Solid Films) and Micro And Nanosystems. 


\begin{abstract}
The increasing agricultural, industrial and domestic activities have led to an alarming increase of organic and inorganic pollutants in the aquatic systems. These pollutants can harm the environment and the living beings; thus the ecological and environmental momentousness of keeping the water resources contamination free has become a sensational concern for researchers. There was an immediate need to develop a methodology for complete removal of contaminants from water resources for sustainable co-existence of all creatures. Conventional water treatment processes like adsorption, coagulation, etc. have high operational costs and produce secondary pollutants. Other traditional methods have proven to be limited techniques due to fast charge recombination, less visible light usage, etc. This led to the emergence of photocatalysis as a propitious environment friendly process for water purification. The employment of semiconductor catalysts in photocatalysis has proven to be potent in degradation of variety of organic impurities to minimally hazardous substances. This paper reviews the potential of cadmium sulphide-based photocatalysts for organic dye degradation and its superiority over other heavily exploited photocatalysts. The complete mechanism of photocatalysis and the degradation of pollutant have been discussed.
\end{abstract}

Keywords: Photocatalysis, Water purification, CdS-based nanocomposites, Mechanism, Organic pollutant, Reactors

\section{Introduction}

Water resources are in need of regular quality checks in order to make them fit on sustainable basis [1]. Henceforth quality along with the quantity of water decides its availability [2]. During the last two decades, some of the major reasons that have become a sole reason behind the rise in the amount of organic impurities in water resources are population growth, rapid industrialisation and continued advancements in technologies [3]. The water pollutants are classified into three major categories; physical (smell, colour, etc), chemical (inorganic/organic compounds), and biological (pathogens) [4]. The release of toxic organic pollutants into water resources is directly proportional to the extent of industrial growth, not to mention the harm and hazard they pose to the environment [5]. The complicated amalgam of biological along with chemical constituencies depicting varied ecological effects, based on the origin of the pollutant are called industrial effluents, for example, food, pharmaceutical, textile, etc [6]. Many times, water treatment processes may lead to the formation of carcinogenic or mutagenic disinfection by-products (DBPs), for example haloacetic acids (HAAs), as a result of reactions occurring between natural organic matter and disinfectants such as chlorine or chloramines [7]. Organic impurities need more attention in comparison to the others as they have prevalent carcinogenic impacts, even upon being exposed to minimal amounts $[8,9]$. The organic dyes are usually distinguished depending on their chromophore group [10]. Air transportation via vapours and water transportation via dust particles and sediments from source to a new environment has also been reported in organic pollutants, thus making them even more threatening [11]. Although few biotic impurities adulterate both surface and groundwater. Groundwater adulteration has been the key link between humans and these hazardous substances [12]. High-molecular-weight organic pollutants are considered to be the typical refractory pollutants, the presence of which creates issues in the water-treatment machinery [13]. The degradation of refractory pollutants is challenging because of the inefficiency in the present water-treatment machineries in treating the former [14], as they have become immune to the decomposition of microbes in the presence of air in traditional biotic purification methods [15]. Major issues regarding the synthetic dyes are their adverse effects in the environment. They inhibit aquatic photosynthesis, deplete dissolved $\mathrm{O}_{2}$ and are extremely toxic to the flora, fauna and human beings. For example, the generated aromatic amines due to the anaerobic degradation of synthetic dyes such as azo dyes have found to be carcinogenic [16]. The photocatalytic degradation (PCD) process has emerged as an advantageous alternative in the field of small amounts of refractory pollutants containing wastewater treatment $[17,18]$. The complete mineralisation of wastewater at a low cost makes PCD superior to other processes [19]. An efficient photo-catalyst must be responsive to light, should be able to make use of visible or near ultraviolet light, unreactive (biologically and chemically), stable under illumination, not prone to photo-corrosion, inexpensive and non-toxic [19]. Semiconductor materials have been alluring scientists 
because of their possession of novel characteristics and potential applications [20,21]. Various studies have established that semiconductor photocatalysts in their nano range are more beneficial than their bulk counterparts [22]. The reduction of the size of a material to nanoscale gives rise to new chemical and physical properties [2]. The surface energy per particle significantly rises in the nano range [23]. This increase in surface energy speeds up the extraction of pollutants at even minute amounts of nano-catalysts [24]. As a result of requirement of a lower amount of nano-material in comparison to its bulk counterparts, lesser waste generation takes place by the use of nanocatalysts, specifically in posttreatment [25]. $\mathrm{TiO}_{2}$ and $\mathrm{ZnO}$ have been amongst the heavily exploited photocatalysts in pollutant degradation, their stability, high photosensitivity, wide band gap being some of the reasons among the others [26-29]. Usually in the case of wide band gap photocatalytic materials, like $\mathrm{TiO}_{2}$, they tend to only absorb UV light. For example, $\mathrm{TiO}_{2}$ possesses a $3.2 \mathrm{eV}$ wide band gap and absorb ultraviolet radiations only with wavelength less than 387 nano metres, resembling nearly three to five percent of the entire solar energy. This leads to certain limitations to the photocatalytic potency of $\mathrm{TiO}_{2}[30$ 32]. On the other hand, small band gap materials are known to absorb large part of visible light [33]. As already known, metal sulphides possess a convenient conduction band location and relatively small band gap, which in case of cadmium sulphide is $2.4 \mathrm{eV}$, thus making it a suitable choice as a photocatalyst [34]. $\mathrm{CdS}$, as a vital II-VI semiconductor possessing a 2.40 $\mathrm{eV}$ wide band gap and $2.4 \mathrm{~nm}^{2}$ Bohr radius has been deployed as a photocatalyst [35-37]. The existence of discreet band structure in the semiconductor domain is a result of quantum confinement, leading to the production of excitons upon illuminating with light [38]. The metallic nanostructures show the surface plasmon resonance (SPR) that regulate the absorption and scattering properties [39]. The interaction of the photo-induced excitons and plasmons occurs metal-semiconductor interphase. This results in flow of energy across their junctions, henceforth promoting charge transfer and charge separation [40]. The electrons and holes generated due to the photoexcitation in $\mathrm{CdS}$ show high recombination rates as a result of their narrow band gap. This along with the low photostability and high toxicity of $\mathrm{CdS}$ limits its photocatalytic efficiency [41-43]. However the usage of befitting electron acceptors such as metals
[44], carbon derivatives [45], and other semiconductors having suitable band structures [46, 47] can help in lowering the recombination rate of charge carriers in semiconductors.

This review article discusses current advances in the various $\mathrm{CdS}$ based nanocomposites used for photocatalytic degradation of organic pollutants. Homogeneous and heterogeneous are the two pathways of photocatalytic degradation of organic pollutant. The mechanism involved in both these photocatalysis as well as that of the degradation of dye has been schematically discussed in detail. Photocatalytic reactors and their role in photocatalysis have also been highlighted.

\section{Nanomaterials}

A well famous lecture in 1959 by Nobel prize winner, Richard P. Feynman on "nanotechnology" quoted, "There's Plenty of Room at the Bottom" [48]. Since then, uncountable ground breaking progresses were made in the nano-technology arena. According to ISO/TS 80004 , nanomaterial is "material in which any one of the outermost proportions lies in the nano-range or it has internal or surface structure in the nano-scale", with nanoscale defined as the "length range lying between 1-100 nm" [49]. It has been found that these materials possess size dependent physicochemical properties, e.g. the optical properties, thus making them substances of great importance. For example, a 20 nano metre gold, platinum, silver, and palladium nano particles possess wine red colour, yellowish grey, black and deep black colours, respectively [50]. These materials can be classified as 0-D (quantum dots), 1-D (surface films), 2-D (strands or fibres) or 3-D (particles), based on their overall shape [51]. Several methods are being put in place for synthesising nano structure materials, such as chemical reduction [52], electrochemical reduction [53], photo-chemical reactions in reverse micelles [54], and bio-synthesis $[18,55-60]$. Nanoparticles being complex particles in nature comprise of three layers i.e. (a) the surface layer, (b) the shell layer, and (c) the core, which is the centre of the nanoparticle and is commonly referred as the nanoparticle itself [61]. It is because of these special properties that these materials became a topic of immense interest for scientists in various fields, also their mesoporous nature making them an exceptional choice in drug delivery [62, 63], biological and chemical sensing $[64,65]$, gas sensing [66], $\mathrm{CO}_{2}$ 
capturing [67] and other related applications [68]. Properties like large fraction of atoms being present on the surface, high surface energy, receded structural demerits, that are a product of their size which is in nano range, are the ones that make them superior to their bulk counterparts. Huge surface area-volume proportion is a result of their small dimension leading to increased surface dependent characteristics. The energy-band construction and charge carrier density in these substances are tuneable which is not found in their bulk form, and thus change their optical and electronic properties [69]. Nanoparticles (NPs) attract higher attention these days because of their potential applications in different fields [70].

\section{Nanocomposites in Pollutant Degradation}

Nano-composite is a multi-phase solid material with one of the phases having 1,2 or 3 dimensions $<10 \mathrm{~nm}$ or the repetitive distances between the varied phases constituting the composite lies in nanometre range. They are used to motif and fabricate novel substances with unparalleled pliability and betterment in their physical and chemical characteristics [71, 72]. The interface area between the matrix and reinforcement phase(s) is slightly higher than that for traditional composites resulting in unusually high surface area to volume ratio [73]. There is a visible effect on the bulk scale characteristics of the composite upon a comparatively minute level of nano-scale adulteration. The alignment and placement of unsymmetrical nano-particles, discrepancy in heat related properties at the interface, and poly-dispersity of nanoparticles fundamentally influence the viable thermal conductance of nano-composites [74]. The efficacy of the nano-particles is such that the quantity of material appended is usually just around $0.5-5 \%$ by wt. Nanocomposites can drastically upgrade properties like mechanical properties involving strength, modulus, electrical conductivity, thermal stability, etc. Nanocomposites are found to be of different types based on their constituent components. CMCs (ceramic matrix composites) consist of ceramic fibres dispersed in a ceramic dispersion medium. In an ideal condition, both components are evenly dispersed into each other with the aim of engendering discrete characteristics [75] along with other protective properties [76]. In the case of metal matrix nanocomposites, CNT-metal matrix composites are emerging as one of the more essential nano-composites. It is being made in order to make use of the immense tensile strength and electrical conductivity of CNTs [77]. In a simplest scenario, precise addition of nano particulates into a polymeric medium magnifies its efficiency, frequently drastically, via mere capitalization on the type and characteristics of the nano-scale add on. This method effectively yields increased efficiency composites, upon even addition of the filler and if the filler is of enhanced quality than that of the matrix [78]. Doping is another method of synthesising composites, which can be employed as photocatalysts. Numerous studies on metal-doped $\mathrm{TiO}_{2}$ have been conducted in order to test the increase in photocatalytic efficiency for degradation of organic pollutants under UV and visible light irradiation. Fe, Sn, Pt were some of the doping metals chosen, among other transition metal ions. The transition metal ions have more than one valence states. Doping them into the pure crystal structure will be the same as the introduction of crystal defects in the lattice. These will then behave as shallow traps for the excitons which will decrease the recombination rate and increase the efficiency [79-82]. Nanocomposites that are capable of responding to an external stimulus are of immense interest. This superficial impetus can acquire various conformations. Magnetic materials are capable of responding to both electrical and magnetic stimuli, hence making them ultimately useful. The magnetic field can penetrate deeper thus affecting an increased nano-composite area [83]. The recovery of the nano-catalysts is the biggest challenge in photocatalytic degradation, which can be faced with the help of magnetic nanoparticles or nanocomposites for liquid-phase reactions such as hydrogenation, aerobic oxidation, carbonylation, etc. Traditionally, the nanocatalysts are removed by high-speed centrifugation or sometimes even addition of extra chemicals, which can defeat the whole purpose of pollutant degradation. But, the ability of magnetic particles to respond to magnetic and electrical stimuli ease up their isolation from the solution and simplify the post-reaction processing and catalyst recycling. This holds true for even very fine and miniscule particulate catalysts [84].

\section{Mechanism of Photocatalysis}

Homogeneous and heterogeneous are the two types of photo-catalysis. The reactants and photo catalysts remain in the identical juncture in former. Ozone and photo Fenton systems $\left(\mathrm{Fe}^{+} \& \mathrm{Fe}^{+}-\mathrm{H}_{2} \mathrm{O}_{2}\right)$ 
are some of the homogeneous photocatalysts that have been used time and time again, with $\mathrm{OH}$ being the reactive species which serves different purposes. $\cdot \mathrm{OH}$ generation through ozone can occur via 2 pathways [85].

$\mathrm{O}_{3}+\mathrm{h} v \rightarrow \mathrm{O}_{2}+\mathrm{O}(1-\mathrm{D})$,

$\mathrm{O}(1-\mathrm{D})+\mathrm{H}_{2} \mathrm{O} \rightarrow \cdot \mathrm{OH}+\cdot \mathrm{OH}$,

$\mathrm{O}(1-\mathrm{D})+\mathrm{H}_{2} \mathrm{O} \rightarrow \mathrm{H}_{2} \mathrm{O}_{2}$,

and

$\mathrm{H}_{2} \mathrm{O}_{2}+\mathrm{h} v \rightarrow \cdot \mathrm{OH}+\cdot \mathrm{OH}$.

Following is the mechanism of $\cdot \mathrm{OH}$ production via Fenton system [86].

$\mathrm{Fe}^{2+}+\mathrm{H}_{2} \mathrm{O}_{2} \rightarrow \mathrm{HO} \cdot+\mathrm{Fe}^{3+}+\mathrm{OH}^{-}$,

$\mathrm{Fe}^{3+}+\mathrm{H}_{2} \mathrm{O}_{2} \rightarrow \mathrm{Fe}^{2+}+2(\mathrm{HO} \cdot)+\mathrm{H}^{+}$,

and

$\mathrm{Fe}^{2+}+\mathrm{HO} \rightarrow \mathrm{Fe}^{3+}+\mathrm{OH}^{-}$,

In heterogeneous catalysis, the catalyst and reactants are in different phases, transition metal oxides and semiconductors being the most frequently used photocatalysts, possessing unique characteristics. Metals have continuous electronic states whereas in semiconductors, there exists a void energy region which is depleted of any energy levels that can promote electron hole recombination in the solid. This empty region extending from the top to the bottom of the valence band and the conduction band, respectively, is termed as band-gap [87]. In one mechanism of the oxidative reaction, a hydroxyl radical is produced as a result of the reaction between positive holes and surface moisture. The beginning of the reaction is marked by the production of excitons upon light illumination on the metal oxide (MO) surface:
$\mathrm{MO}+\mathrm{h} v \rightarrow \mathrm{MO}\left(\mathrm{h}^{+}+\mathrm{e}^{-}\right)$,

Following are the oxidising reactions as a result of the photo-catalytic phenomena:

$\mathrm{h}^{+}+\mathrm{H}_{2} \mathrm{O} \rightarrow \mathrm{H}^{+}+\cdot \mathrm{OH}$,

$2 \mathrm{~h}^{+}+2 \mathrm{H}_{2} \mathrm{O} \rightarrow 2 \mathrm{H}^{+}+\mathrm{H}_{2} \mathrm{O}_{2}$

and

$\mathrm{H}_{2} \mathrm{O}_{2} \rightarrow 2(\cdot \mathrm{OH})$.

Following are the reducing reactions as a result of the photo-catalytic phenomena:

$\mathrm{e}^{-}+\mathrm{O}_{2} \rightarrow \cdot \mathrm{O}_{2}^{-}$,

$\cdot \mathrm{O}_{2}^{-}+\mathrm{H}_{2} \mathrm{O}+\mathrm{H}^{+} \rightarrow \mathrm{H}_{2} \mathrm{O}_{2}+\mathrm{O}_{2}$,

and

$\mathrm{H}_{2} \mathrm{O}_{2} \rightarrow 2(\cdot \mathrm{OH})$.

We can see that the hydroxyl radical generation takes place in both. These $\cdot \mathrm{OH}$ show highly oxidative behaviour and are non-selective, with $\mathrm{E}_{0}$ (redox potential) $=+3.06 \mathrm{~V}[88]$.

Fig. 1 shows the general mechanism of photocatalysis. The electronic construction of the semiconductor photocatalyst comes into picture now, which consists of the valence and the conduction band. The energy difference between them is known as the band gap of the material. All the electrons and holes are in the valence band in their unexcited state [24]. Upon excitation by a light source, be it visible or UV, having energy equivalent or higher than its band-gap, the electrons jump from valence to conduction band. The light induced electrons and holes also can recombine in bulk or on the semiconductor surface, releasing heat or photons. The electrons \& holes reaching the facet of the semiconductor then reduce or oxidise the adsorbed reactants (i.e., pollutants) [89].

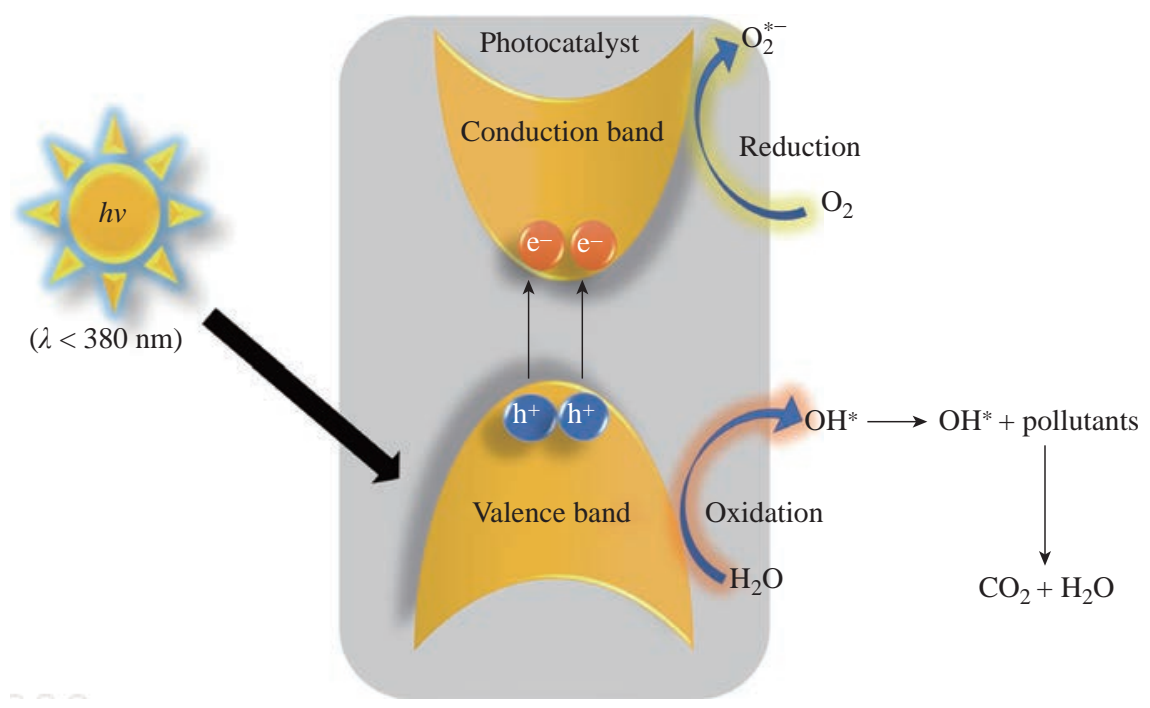

Fig. 1 Process that occurs upon photoexcitation of catalyst. 
Synthetic dyes have become one of the most readily available organic pollutants in recent times. Azo bond $(-\mathrm{N}=\mathrm{N}-)$ is known to be the weakest chemical bond in the chemical structure of dye molecules. The attack of $\cdot \mathrm{OH}$ radicals at this bond and breaking of the conjugate structure is what marks the initiation of the degradation in photocatalysis [90]. After that, the intermediate products of the degradation undergo radical chain reaction with $\mathrm{O}_{2}$ and in due course fester to form $\mathrm{H}_{2} \mathrm{O}$ and $\mathrm{CO}_{2}$ [91]. The response of dyes in the decomposition machinery depends on their chemical construction [92]. Dyes with complicated makeup commonly show lesser degradation upon light illumination, and the adsorption trends rely on the functional groups $[93,94]$. Another tenacious organic pollutant that has profusely been under research are pesticides. The photo-degradation of many main categories of pesticides, herbicides, etc has been previously talked about [95].

\section{Photocatalytic Reactors}

We know that an arena is required for carrying out photocatalysis, this purpose being served by the photocatalytic reactors. In order to carry out the photocatalysis with maximum possible efficiency, the geometry of the reactor has to be in such a way that there is coherent contiguity between the contaminant and the photocatalyst and also the latter should be able to mop up enough number of photons from the light sources [96]. An ideal photocatalytic reactor, should be having high speed mass transferring system, high kinetic rate, and large reaction surface area. The basic design of the photo-catalytic reactor comprises of a source of light and a reactor anatomy. The decomposition process of biotic impurities by the photo-catalyst in the reactor takes place by mass transferring the associated reactants to the catalyst facet, i.e., adsorption or desorption, and subsequently photo-decomposition of the reactants [97]. PMR (photocatalytic membrane reactor) is an integrated machinery of photo-catalysis and membrane-filtration methods in order for a rich permeate production [98]. Slurry PMR is the most common photocatalytic reactor. It consists of freely suspended photocatalysts in the reactor structure [99]. The huge surface area of suspended particles inside the slurry reactor increases the rate of mass transferring among the substrates and catalysts and therefore enhances the photo-catalytic potency [100]. There are two groups of slurry PMR, separated photocatalytic membrane reactor (SPMR) and incorporated photocatalytic membrane reactor (IPMR) [101].

Fig. 2 shows another type of reactor, i.e., a PTR (parabolic trough reactor), which is an enhancement of traditional photo-reactor.

It comprises of see-through trough collectors for wastewater flux. The collector facet is reflective and parabolic [102]. The drawbacks of PTR were overcome by the invention of CPC (Compound Parabolic Concentrator) reactor (Fig. 3).

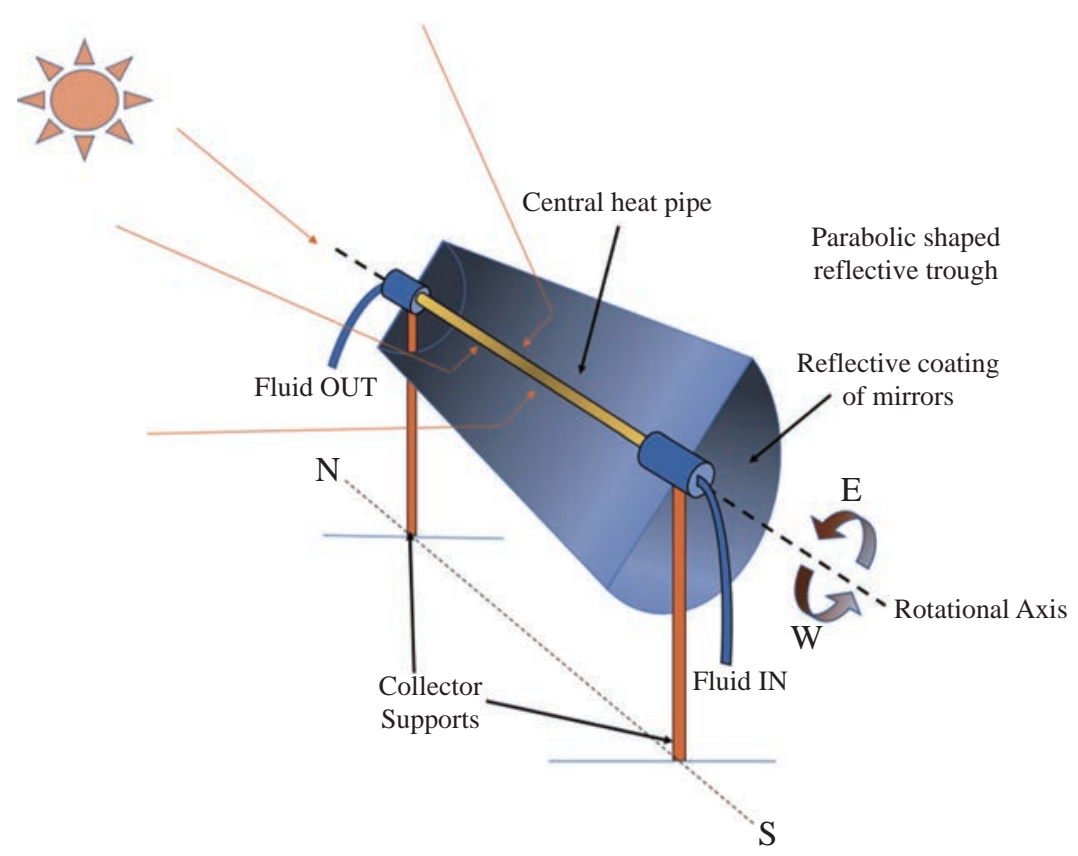

Fig. 2 Schematic of parabolic trough reactor. 


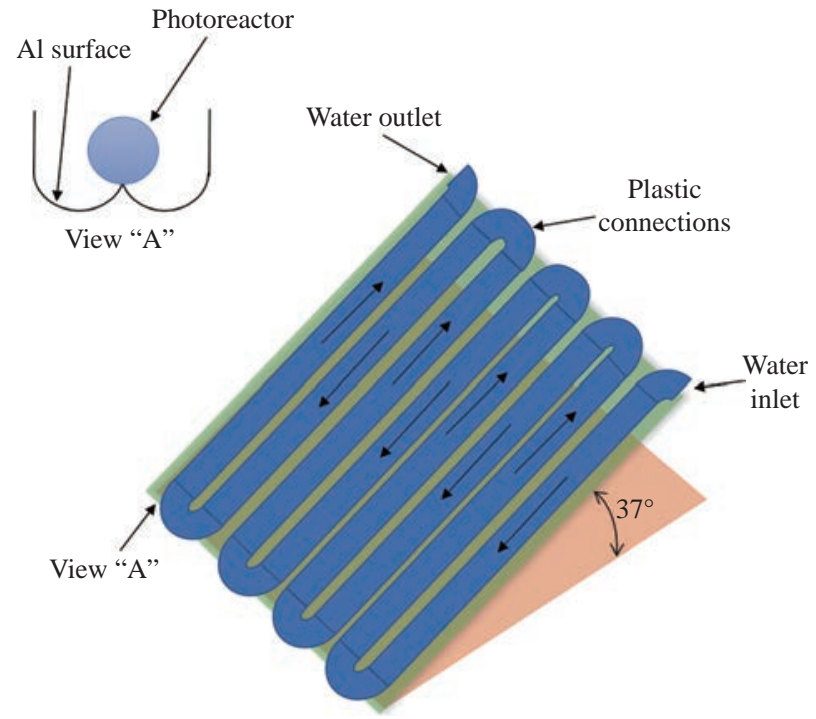

Fig. 3 Schematic of a typical compound parabolic concentrator.

It is a merger of the excellent properties of both parabolic concentrator and fixed flat setup [103]. CPC system includes numerous cylinder shaped ducts along with stagnant collectors having reflective facet making a baroque around the ducts [104].

\section{Organic Pollutants}

The traditional water treatment technologies have consistently failed in complete decomposition of biotic impurities in aqueous media, thus making them of more concern [105]. Organic dyes, pesticides, oils, greases, and so on are some of the organic contaminants among others [106]. Their chemical stability and less biodegradability in water, make them potentially hazardous to the environment $[107,108]$. Organic dyes absorb and then reflect the sunlight that enters the water. This hinders the bacterial growth resulting in difficulty with impurity degradation [109]. When the organic pollutants are released into the water bodies, they create numerous problems in the aquatic ecosystem. These problems can include clogging of sewage treatment plants, increase in biochemical oxygen and adverse effects on aquatic biota [110, 111]. Organic pollutants are of numerous types. VOCs (volatile organic compounds) are proven hazardous and mutagenic. They also play a major role in the thinning of the ozone layer alongside their aid to global warming [112]. These contaminants cause gene mutations and thus have become the ones to blame for the appearance of bacteria that are resistant to antibiotic [113]. POPs (persistent organic pollutants), are organic compounds that are also termed as "forever chemicals" due to their immunity towards environmental degradation through chemical, biological and photolytic processes [114]. When they are released in the ecosystem, they don't easily degrade and can stay as it is for extreme durations, for ex, PCBs (polychlorinated biphenyls), not to mention their entrance in food-chains and accumulation to fatal levels for the living beings at top of the food-chain [11]. Many POPs have been extensively used in the present as well as the past as pesticides, solvents, pharmaceuticals, and industrial chemicals. Although few of them are found in nature, for example in volcanoes and various biosynthetic pathways, most of them are man-made [115] through total synthesis. Organic pollutants come along with the ease of their transportation from the source to a fresh environment via air (in the form of vapor) or water currents (in the form of dust particulates or sediments), making them even bigger threat [11]. NOM (natural organic matter), is the term used to refer to an aggregation of biotic substances that are found in nature upon plant and animal material degradation [116]. Natural organic matter components are heterogeneous mixture of complex hydrophobic and hydrophilic organic materials. The microbial byproducts are the hydrophilic components containing a greater amount of carbon chains and nitrogen containing compounds [117]. The hydrophobic fraction is composed of the humic substances (HS) which demonstrate comparatively high SUVA (specific ultraviolet absorbance) values owing to the comparatively larger proportion of aromatic carbon, double bonds, etc [4]. The compounds that cannot be degraded easily and/or demonstrate a lower proportion of biological and chemical oxygen demand (BOD/ COD) are grouped as refractory $[118,119]$. These compounds are quite immune to biodegradation, are malignant and impede bacterial growth, thus posing a threat water and wastewater treatment systems [120]. The typical refractory pollutants are the organics having high molecular weight [121]. They are inclusive of lignin. tannic acid, chlortetracycline, and EDTA coming from kraft mills, electroplating and pharmaceutical industries, etc. [13].

\section{Photo-catalytic Organic Conta- minant Decomposition}

Semiconductor based photocatalysis has become more alluring in comparison to the traditional chemicaloxidation pathways for degradation of pernicious 
substances in water at appropriate conditions with economical and clean solar light and atmospheric dioxygen serving as the source of energy and oxidant, respectively, into $\mathrm{H}_{2} \mathrm{O}, \mathrm{CO}_{2}$ and inorganic ions [122]. Recent studies show that the organic substrates strongly absorb the visible light. Therefore visible light augments the Fenton reaction for the decomposition of dye pollutants [123, 124]. These studies have increased the prospective of the employment of visible light in water treatment two folds. Semiconductors: (i) are economical, (ii) are benign, (iii) have large facet area, (iv) possess wide absorption spectrum, (v) showcase tuneable characteristics that could be altered via size curtailment, doping, etc., (vi) afford facility for multielectron transfer mechanism and (vii) are capable of extended usage without significant forfeiture of photocatalytic activity, are being used excessively [12, 125127]. The prerequisite for coherent decomposition of dyes is a photocatalyst with befitting band-gap and excellent adsorption trends in the visible arena [128]. CdS being a material of direct band gap of $\sim 2.4$ electron volt is a propitious substance, the possibility of upgradation of its photocatalytic pursuit via activation by other materials adds to its charm [129]. We consider an example of $\mathrm{CdS}$ and $\mathrm{ZnS}$ nanoparticles and their nanocomposites, respectively, in order to get a clarity of the photo-catalytic activity shown by nanoparticles and nanocomposites. When zinc sulphide and cadmium sulphide are illuminated by light, they produce $\mathrm{e}^{-}-\mathrm{h}^{+}$ pairs which are strong oxidizing agents and reducing agents, respectively:

$\mathrm{ZnS}+h v \rightarrow \mathrm{h}^{+}+\mathrm{e}^{-}$and $\mathrm{CdS}+h v \rightarrow \mathrm{h}^{+}+\mathrm{e}^{-}$.

Following are the oxidising and reducing reactions:

$\mathrm{OH}^{-}+\mathrm{h}^{+} \rightarrow \cdot \mathrm{OH}$ and $\mathrm{O}_{2}+\mathrm{e}^{-} \rightarrow \mathrm{O}_{2}^{-}$.

It is to be noted that the hydroxyl radical serves the purpose of the primary oxidant in the decomposition mechanism. $\mathrm{O}_{2}$ checks the re-integration of electronhole pairs. $\mathrm{CO}_{2}$ and $\mathrm{H}_{2} \mathrm{O}$ among others emerge as the end products of a complete reaction $[130,131]$ :

Organic Pollutant $+\cdot \mathrm{OH} \rightarrow$ products

$\left(\mathrm{CO}_{2}+\mathrm{H}_{2} \mathrm{O}+\mathrm{NH}_{4}^{+}+\mathrm{NO}_{3}^{-}+\mathrm{SO}_{4}{ }^{2-}+\mathrm{Cl}^{-}\right)$.

The photodegradation of methylene blue (MB), a dye, in terms of absorption spectra and as a function of radiation time in the presence of zinc sulphide and cadmium sulphide nano particles under visible radiations has been studied by many people [129].

It was found that the sharpness of the adsorption peaks gingerly plummeted as the duration of subjection grew. The amount of methylene blue was halved after 210 minutes in the case of $\mathrm{CdS}$ photocatalyst. It gained the upper hand by demonstrating a decomposition competence of $63 \%$ after 360 minutes. On the other hand $\mathrm{ZnS}$ showed an efficiency of merely $30 \%$ after 360 minutes [132]. The contrast in the photo-catalytic schemes of zinc sulphide and cadmium sulphide nanoparticles can be completely attributed to their band gap. Fig. 4 shows the band structures of zinc sulphide and cadmium sulphide.

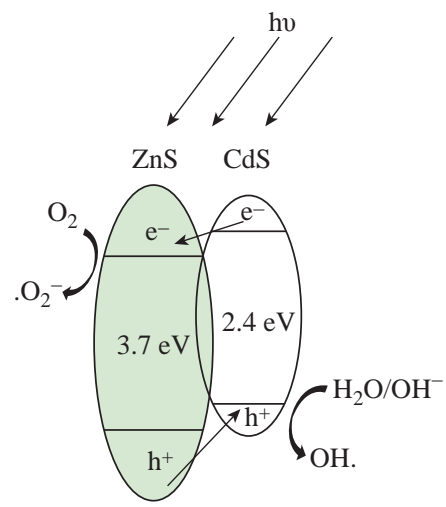

Fig. 4 Band construction schematics of zinc sulphide and cadmium sulphide nano-particles.

$\mathrm{ZnS}$ has a large band gap. Hence it showcases a weak reaction to visible radiation, even though its $\mathrm{CB}$ (conduction band) bottom potential is adequately negative. In disparity, $\mathrm{CdS}$ is an excellent absorber of visible light, the quality attributed to its small band gap. Although the $\mathrm{CB}$ bottom potential of $\mathrm{CdS}$ is close to that of $\mathrm{O}_{2} / \mathrm{O}_{2}^{-}(-0.046 \mathrm{eV}$ vs. SHE) [133]. In this case, the dispersion of CdS was improved by the separation feature of $\mathrm{ZnS}$, leading to production of higher surface area and generation of a greater number of active sites. The band structure illustrates the higher negativity of the conduction band of CdS than that of $\mathrm{ZnS}$. The photo-generated electrons in the conduction band of CdS were transferred to the conduction band of $\mathrm{ZnS}$ whilst the holes remain in the valence band of $\mathrm{CdS}$ due to the potential gradient created at the interface. This leads to decrease in charge recombination rate and strengthens the charge separation effect, thus increasing the efficiency.

A study done by Liu et. al. shows that for different dyes, the $\mathrm{ZnS} / \mathrm{CdS}$ composites own stronger decomposition capability than the constituent $\mathrm{ZnS}$ and CdS individually [134]. Moreover, it is even found to surpass the degradation capability of mercantile anatase $\mathrm{TiO}_{2}(\mathrm{P}-25)$ for Methylene Blue, Rhodamine B. The above graphs show that the decomposition rates of $\mathrm{ZnS} / \mathrm{CdS}$ composite rises in comparison to 
Table 1 Comparison of degradation efficiencies of different CdS based nanocomposites

\begin{tabular}{|c|c|c|c|c|c|}
\hline Catalyst & Pollutant & Constant parameter & Degradation (\%) & Catalyst preparation method & Reference \\
\hline $\mathrm{Au} / \mathrm{CdS}$ & Rhodamine b (Rh B) dye & $\begin{array}{l}\text { Light source - UV visible } \\
\text { Irradiation time }-75 \mathrm{~min}\end{array}$ & $\sim 95 \%$ & Facile & {$[136]$} \\
\hline $\begin{array}{l}\text { PVAassisted } \\
\mathrm{Bi}_{2} \mathrm{WO}_{6} / \mathrm{CdS}\end{array}$ & $\begin{array}{l}\text { Metronidazole and } \\
\text { methylene Blue }\end{array}$ & $\begin{array}{l}\text { Light source }- \text { Visible } \\
\text { irradiation time }-100 \mathrm{~min}\end{array}$ & $\begin{array}{l}70 \% \text { (Metronidazole) } \\
92 \% \text { (Methylene blue) }\end{array}$ & Hydrothermal & {$[137]$} \\
\hline CdS / Graphene & Methyl orange & $\begin{array}{l}\text { Light source }- \text { Visible } \\
\text { irradiation time }-300 \mathrm{~min}\end{array}$ & $90 \%$ & Hydrothermal & [138] \\
\hline CdS / RGO & Methylene blue & $\begin{array}{l}\text { Light source }- \text { Visible } \\
\text { irradiation time }-150 \mathrm{~min}\end{array}$ & $77 \%$ & $\begin{array}{l}\text { PLAL (Pulsed laser-ablation } \\
\text { in liquids) }\end{array}$ & [139] \\
\hline $\mathrm{CdS} / \mathrm{TiO}_{2}$ & Phenol & $\begin{array}{l}\text { Light source }- \text { Visible } \\
\text { irradiation time }-4 \mathrm{~h}\end{array}$ & $40 \%$ & Reverse micelle process & {$[140]$} \\
\hline $\mathrm{CdS} / \mathrm{ZnO}$ & Methylene blue & $\begin{array}{l}\text { Light source }- \text { Visible } \\
\text { irradiation time }-300 \mathrm{~min}\end{array}$ & $71.1 \%$ & Precipitation method & {$[141]$} \\
\hline $\mathrm{CuS} / \mathrm{CdS}$ & Methylene blue & $\begin{array}{l}\text { Light source }- \text { Visible } \\
\text { irradiation time }-10 \mathrm{~min}\end{array}$ & $99.97 \%$ & Hydrothermal & {$[142]$} \\
\hline $\mathrm{Fe}_{3} \mathrm{O}_{4} / \mathrm{CdS}$ & Methyl orange & $\begin{array}{l}\text { Light source }-\mathrm{UV} \\
\text { Irradiation time }-50 \mathrm{~min}\end{array}$ & $89 \%$ & Sono-chemical & [143] \\
\hline $\mathrm{NiS} / \mathrm{CdS}$ & Quinoline & $\begin{array}{l}\text { Light source }- \text { Visible } \\
\text { irradiation time }-10 \mathrm{~h}\end{array}$ & $81 \%$ & Facile & [144] \\
\hline $\mathrm{SnS}_{2} / \mathrm{CdS}$ & Methyl orange & $\begin{array}{l}\text { Light source }- \text { Visible } \\
\text { irradiation time }-150 \mathrm{~min}\end{array}$ & $95.45 \%$ & Chemical & {$[145]$} \\
\hline $\begin{array}{c}\mathrm{TiO}_{2} \text { nanotubes } / \\
\mathrm{ZnO} / \mathrm{CdS}\end{array}$ & Alizarin red S (ARS) & $\begin{array}{l}\text { Light source - Ultraviolet } \\
\text { irradiation time }-180 \mathrm{~min}\end{array}$ & $75 \%$ & Electrochemical method & {$[146]$} \\
\hline
\end{tabular}

$\mathrm{ZnS}$ and mercantile anatase $\mathrm{TiO}_{2}$. It touches $85 \%$ for Methylene Blue and 84\% for Rhodamine B [134]. The above example of $\mathrm{ZnS}$ and $\mathrm{CdS}$ nanoparticles and nanocomposites, respectively helps us to understand the rise in the photodecomposition potency of the catalysts when they are in composite form, as compared to their potency in particulate form. CdS has a band gap of $2.4 \mathrm{eV}$ which is narrow in comparison to other wide band gap semiconductors such as titanium dioxide. When CdS nanoparticles are used as catalysts for photocatalytic degradation, they absorb in some parts of UV as well as a large part of visible region which makes it more feasible. The disadvantage coming in as the poor charge separation and high charge recombination, as a result of small band gap can be overcome when $\mathrm{CdS}$ based nanocomposites are used as photocatalyst. The absorption range is broadened, along with that, the efficiency of the catalyst increases since increased charge separation is achieved [135].

There are numerous studies that have been carried out on different $\mathrm{CdS}$ based nanocomposites. In a study it was shown that $\mathrm{Au}-\mathrm{CdS}$ nanocomposite prepared via facile synthesis was able to degrade $95 \%$ rhodamine b dye under UV visible light source [136]. In other researches as well, nanocomposites like CdS-Graphene and $\mathrm{CuS}-\mathrm{CdS}$ have been reported to show degradation efficiency up to $90 \%$ and $99.97 \%$, respectively [137, 138]. The number of cycles for the use of photocatalyst varies depending on the type of composite synthesized. For the $\mathrm{Bi}_{2} \mathrm{WO}_{6} / \mathrm{CdS}$ nanocomposite, $92 \%$ degradation efficiency was achieved for Methylene Blue dye [133]. The catalyst was used for 5 cycles, with the efficiency reducing significantly by the $5^{\text {th }}$ cycle. This reduction in the efficiency with subsequent cycles can be a result of blocking of the active sites. Also, the separation of the catalysts from the solution serves as a challenge due to the nano size of the photocatalysts. Table 1 shows how various CdS based nanocomposites are being synthesised by various methods and are being employed for UV or visible light induced photocatalysis, with considerable efficiency [136-146].

\section{Conclusions}

Water makes up about $71 \%$ of the earth's surface. This clearly indicates the immediate need to keep the water resources contamination free. The nondegradable and mutagenic properties of organic and inorganic pollutants have made them a serious threat to both environment and its creatures, including humans. Organic dyes, POPs, NOMs, VOCs constitute the list of organic pollutants. We, 
in this paper, made an attempt to summarise the role of organic pollutants in degrading the water quality, hindering the food chain and hazarding the human health and their effective treatment by photocatalysis. Photocatalysis has emerged as an effective way of water treatment upon the continuous failures of conventional methods in doing so. The choice of photocatalysts is the key to the success of the former in achieving water purity. Semiconductor nanoparticles and nano-composites have constantly proved their worth in the photocatalytic arena in the recent times. Nanoparticles, as already known, have high surface area to volume ratio, making them an excellent choice for deployment as catalysts. Also, the synthesis of these nanoparticles and nanocomposites can be done via various pathways, physical, chemical or biological. The increasing biological synthesis of these materials these days tends to lessen their toxicity, making them mild yet effective. This also gives rise to a plethora of advantages in using them as catalysts for water purification. We have highlighted the superiority of cadmium sulphidebased nanocomposites as efficient photocatalysts against other semiconductor nanoparticles or nano composites. The mechanism of photocatalysis can be both homogeneous and heterogeneous, with the former using ozone or photo-Fenton systems as photocatalysts and the latter using transition metal oxides or semiconductors as photocatalysts. Visible light is being employed extensively for photocatalytic degradation of organic dyes these days. The photocatalytic mechanism takes place in the photocatalytic reactors, the kind of which brings a great impact on the technique. With time, many variations are being made in these reactors, thus increasing the degradation efficiency and quality. Overall, this paper highlights the perks of employment of cadmium sulphide-based photo-catalysts for the decomposition of biotic impurities, clearly showing its high degradation efficiency. However, the need to decrease the irradiation time of the visible or UV light during the process for faster degradation still needs to be catered to, opening new pursuable research avenues.

\section{References}

[1] M.P. Herbst, S. Jooste, P. Kempster, et al., Needs assessment and development framework for a tested implementation plan for the initialisation and execution of a National Toxicants Monitoring Programme (NTMP),
2003.

[2] T. Pradeep, Noble metal nanoparticles for water purification: a critical review. Thin Solid Films, 2009, 517: 6441-6478.

[3] K. Rajeshwar, M.E. Osugi, W. Chanmanee, et al., Heterogeneous photocatalytic treatment of organic dyes in air and aqueous media. Journal of Photochemistry and Photobiology C: Photochemistry Reviews, 2008, 9: 171192.

[4] S. Hong, M. Elimelech, Chemical and physical aspects of natural organic matter (NOM) fouling of nanofiltration membranes, Journal of Membrane Science, 1997, 132: 159-181.

[5] V.V.B. Rao, S.R.M. Rao, Adsorption studies on treatment of textile dyeing industrial effluent by fly ash, Chemical Engineering Journal, 2006, 116: 77-84.

[6] B. Hajem, H. Hamzaoui, and A. M'Nif, Chemical interaction between industrial acid effluents and the hydrous medium, Desalination, 2007, 206: 154-162

[7] S. Mattaraj, C. Jarusutthirak, and R. Jiraratananon, A combined osmotic pressure and cake filtration model for crossflow nanofiltration of natural organic matter, Journal of Membrane Science, 2008, 322: 475-483.

[8] Z.J. Bo, G. Maochu, W.J. Li, et al., Effect of metal doping into $\mathrm{Ce} 0.5 \mathrm{Zr} 0.5 \mathrm{O} 2$ on photocatalytic activity of $\mathrm{TiO}_{2} /$ Ce0. 45Zr0. 45M0. 1OX (M=Y, La, Mn), Journal of hazardous materials, 2007, 143: 516-521.

[9] I. Dror, D. Baram, and B. Berkowitz, Use of nanosized catalysts for transformation of chloro-organic pollutants, Environmental science \& technology, 2005, 39: 12831290.

[10] S.M. Lam, J.C. Sin, A.Z. Abdullah, et al., Degradation of wastewaters containing organic dyes photocatalysed by zinc oxide: a review, Desalination and Water Treatment, 2012, 41: 131-169.

[11] O. Faroon, J.N. Olson, Toxicological profile for polychlorinated biphenyls (PCBs), 2000.

[12] M.R. Hoffmann, S.T. Martin, W. Choi, et al., Environmental applications of semiconductor photocatalysis, Chemical Reviews, 1995, 95: 69-96.

[13] L.C. Chiang, J.E. Chang, and S.C. Tseng, Electrochemical oxidation pretreatment of refractory organic pollutants, Water Science and Technology, 1997, 36: 123-130.

[14] K.H. Kim, S.K. Ihm, Heterogeneous catalytic wet air oxidation of refractory organic pollutants in industrial wastewaters: a review, Journal of Hazardous Materials, 2011, 186: 16-34.

[15] Z. Wu, M. Zhou, Partial degradation of phenol by advanced electrochemical oxidation process, Environmental Science \& Technology, 2001, 35: 26982703.

[16] I.I. Savin, R. Butnaru, Wastewater characteristics in textile finishing mills, Environmental Engineering \& Management Journal (EEMJ), 2008, 7: 859-864.

[17] D.F. Ollis, E. Pelizzetti, and N. Serpone, Photocatalyzed destruction of water contaminants, Environmental Science \& Technology, 1991, 25: 1522-1529.

[18] R.M. Tripathi, R.P. Rao, and T. Tsuzuki, Green synthesis of sulfur nanoparticles and evaluation of their catalytic detoxification of hexavalent chromium in water, $R S C$ advances, 2018, 8: 36345-36352.

[19] A. Mills, R.H. Davies, and D. Worsley, Water purification by semiconductor photocatalysis, Chemical Society Reviews, 1993, 22: 417-425.

[20] Z. Han, H. Zhu, J. Shi, et al., Preparation of mesoporous cadmium sulfide nanoparticles with moderate pore size, Journal of Solid State Chemistry, 2007, 180: 902-906.

[21] Y. Sun, B. Mayers, and Y. Xia, Transformation of silver nanospheres into nanobelts and triangular nanoplates through a thermal process, Nano Letters, 2003, 3: 675- 
679.

[22] C. Allmond, A. Sellinger, K. Gogick, et al., Photochemical synthesis and deposition of noble metal nanoparticles, Applied Physics A, 2007, 86: 477-480.

[23] N. Savage, M.S. Diallo, Nanomaterials and water purification: opportunities and challenges, Journal of Nanoparticle Research, 2005, 7: 331-342.

[24] M. Ni, M.K. Leung, D.Y. Leung, et al., A review and recent developments in photocatalytic water-splitting using $\mathrm{TiO}_{2}$ for hydrogen production, Renewable and Sustainable Energy Reviews, 2007, 11: 401-425.

[25] W. Tang, Q. Wang, X. Zeng, et al., Photocatalytic degradation on Disperse Blue with modified nano- $\mathrm{TiO}_{2}$ film electrode, Journal of Solid State Electrochemistry, 2012, 16: 1429-1445.

[26] S. Sakthivel, B. Neppolian, M. Palanichamy, et al., Photocatalytic degradation of leather dye, Acid Green 16 Using ZnO in the Slurry and Thin Film Forms, 1999, 6: 161-165.

[27] D. Bahnemann, Mechanisms of Organic Transformations on Semiconductor Particles, Springer, 1991: 251-276.

[28] K.I. Okamoto, Y. Yamamoto, H. Tanaka, et al., Heterogeneous photocatalytic decomposition of phenol over $\mathrm{TiO}_{2}$ powder, Bulletin of the Chemical Society of Japan, 1985, 58: 2015-2022.

[29] R.M. Tripathi, A.S. Bhadwal, R.K. Gupta, et al., ZnO nanoflowers: novel biogenic synthesis and enhanced photocatalytic activity, Journal of Photochemistry and Photobiology B: Biology, 2014, 141: 288-295.

[30] U.I. Gaya, A.H. Abdullah, Heterogeneous photocatalytic degradation of organic contaminants over titanium dioxide: a review of fundamentals, progress and problems, Journal of Photochemistry and Photobiology C: Photochemistry Reviews, 2008, 9: 1-12.

[31] X. Chen, S.S. Mao, Titanium dioxide nanomaterials: Synthesis, properties, modifications, and applications, Chemical reviews, 2007, 107: 2891-2959.

[32] M.D. Hernández-Alonso, F. Fresno, S. Suárez, et al., Development of alternative photocatalysts to $\mathrm{TiO}_{2}$ : Challenges and opportunities, Energy \& Environmental Science, 2009, 2: 1231-1257.

[33] M.R. Gholipour, C.T. Dinh, F. Béland, et al., Nanocomposite heterojunctions as sunlight-driven photocatalysts for hydrogen production from water splitting, Nanoscale, 2015, 7: 8187-8208.

[34] K. Zhang, L. Guo, Metal sulphide semiconductors for photocatalytic hydrogen production, Catalysis Science \& Technology, 2013, 3: 1672-1690.

[35] S. Wang, P. Liu, X. Wang, et al., Homogeneously distributed CdS nanoparticles in nafion membranes: preparation, characterization, and photocatalytic properties, Langmuir, 2005, 21: 11969-11973.

[36] M. Bruchez, M. Moronne, P. Gin, et al., Semiconductor nanocrystals as fluorescent biological labels, Science, 1998, 281: 2013-2016.

[37] A.S. Bhadwal, R.M. Tripathi, R.K. Gupta, et al., A. Shrivastav, Biogenic synthesis and photocatalytic activity of CdS nanoparticles, RSC Advances, 2014, 4: 9484-9490.

[38] A.P. Alivisatos, Perspectives on the physical chemistry of semiconductor nanocrystals, The Journal of Physical Chemistry, 1996, 100: 13226-13239.

[39] R.M. Tripathi, S.H. Park, G. Kim, et al., Metal-induced redshift of optical spectra of gold nanoparticles: An instant, sensitive, and selective visual detection of lead ions, International Biodeterioration \& Biodegradation, 2019, 144: 104740

[40] G. Ma, J. He, K. Rajiv, et al., Observation of resonant energy transfer in $\mathrm{Au}$ : CdS nanocomposite, Applied Physics Letters, 2004, 84: 4684-4686.
[41] Y. Xie, G. Liu, and H. Cheng, Crystal facet-dependent photocatalytic oxidation and reduction reactivity of monoclinic WO3 for solar energy conversion, Journal of Materials Chemistry., 2012, 22: 6746-6751.

[42] Y.P. Xie, Z.B. Yu, G. Liu, et al., CdS-mesoporous ZnS core-shell particles for efficient and stable photocatalytic hydrogen evolution under visible light, Energy and Environmental Science, 2014,7: 1895-1901.

[43] X. Yang, G. Lu, B. Wang, et al., Synthesis, growth mechanism and photocatalytic $\mathrm{H} 2$ evolution of $\mathrm{CdS} / \mathrm{CuS}$ composite via hydrothermal method, RSC Advances, 2014, 9: 25142-25150.

[44] E. Elmalem, A.E. Saunders, R. Costi, et al., Growth of photocatalytic CdSe-Pt nanorods and nanonets, Advanced Materials, 2008, 20: 4312-4317.

[45] P. Brown, P.V. Kamat, Quantum dot solar cells. Electrophoretic deposition of CdSe-C60 composite films and capture of photogenerated electrons with n C60 cluster shell, Journal of the American Chemical Society, 2008, 130: 8890-8891.

[46] A. Kongkanand, K. Tvrdy, K. Takechi, et al., Quantum dot solar cells. Tuning photoresponse through size and shape control of $\mathrm{CdSe}-\mathrm{TiO}_{2}$ architecture, Journal of the American Chemical Society, 2008, 130: 4007-4015.

[47] Y. Tak, H. Kim, D. Lee, et al., Type-II CdS nanoparticle$\mathrm{ZnO}$ nanowire heterostructure arrays fabricated by a solution process: enhanced photocatalytic activity, Chemical Communications, 2008, 38: 4585-4587.

[48] A. Hey, Feynman and computation, Perseus Books Publishing, 1999: 1-5.

[49] I. ISO, TS 80004-1: 2010, Nanotechnologies - Vocabulary - Part 1: Core terms, International Organization for Standardization, Geneva, 2010.

[50] E.C. Dreaden, A.M. Alkilany, X. Huang, et al., The golden age: gold nanoparticles for biomedicine, Chemical Society Reviews, 2012, 41: 2740-2779.

[51] J.N. Tiwari, R.N. Tiwari, and K.S. Kim, Zerodimensional, one-dimensional, two-dimensional and three-dimensional nanostructured materials for advanced electrochemical energy devices, Progress in Materials Science, 2012, 57: 724-803.

[52] S. Banerjee, K. Loza, W. Meyer-Zaika, et al., Structural evolution of silver nanoparticles during wet-chemical synthesis, Chemistry of Materials, 2014, 26: 951-957.

[53] Y. Zhang, F. Chen, J. Zhuang, et al., Synthesis of silver nanoparticles via electrochemical reduction on compact zeolite film modified electrodes, Chemical Communications, 2002, 23: 2814-2815.

[54] S. Yi, F. Dai, C. Zhao, et al., A reverse micelle strategy for fabricating magnetic lipase-immobilized nanoparticles with robust enzymatic activity, Scientific Reports, 2017, 7: $1-9$.

[55] R.M. Tripathi, B.R. Shrivastav, and A. Shrivastav, Antibacterial and catalytic activity of biogenic gold nanoparticles synthesised by Trichoderma harzianum, IET Nanobiotechnology, 2018, 12: 509-513.

[56] R.M. Tripathi, R.N. Pudake, B. Shrivastav, et al., Antibacterial activity of poly (vinyl alcohol) — biogenic silver nanocomposite film for food packaging material, Advances in Natural Sciences: Nanoscience and Nanotechnology, 2018, 9: 025020.

[57] R.M. Tripathi, S.J. Chung, Biogenic nanomaterials: Synthesis, characterization, growth mechanism, and biomedical applications, Journal of Microbiological Methods, 2019, 157: 65-80.

[58] R.M. Tripathi, S.Y. Yoon, D. Ahn, et al., Facile Synthesis of Triangular and Hexagonal Anionic Gold Nanoparticles and Evaluation of Their Cytotoxicity, Nanomaterials, 2019, 9: 1774.

[59] R.M. Tripathi, S.J. Chung, Reclamation of hexavalent 
chromium using catalytic activity of highly recyclable biogenic Pd(0) nanoparticles, Scientific Reports, 2020, 10: $1-14$.

[60] R.M. Tripathi, D. Ahn, Y.M. Kim, et al., Enzyme Mimetic Activity of ZnO-Pd Nanosheets Synthesized via a Green Route, Molecules, 2020, 25: 2585.

[61] W.K. Shin, J. Cho, A.G. Kannan, et al., Cross-linked composite gel polymer electrolyte using mesoporous methacrylate-functionalized $\mathrm{SiO}_{2}$ nanoparticles for lithium-ion polymer batteries, Scientific Reports, 2016, 6: 26332.

[62] J.E. Lee, N. Lee, T. Kim, et al., Multifunctional mesoporous silica nanocomposite nanoparticles for theranostic applications, Accounts of Chemical Research, 2011, 44: 893-902.

[63] R.M. Tripathi, A. Shrivastav, and B. Shrivastav, Biogenic gold nanoparticles: as a potential candidate for brain tumor directed drug delivery, Artificial Cells, Nanomedicine, and Biotechnology, 2015, 43: 311-317.

[64] H. Barrak, T. Saied, P. Chevallier, et al., Synthesis, characterization, and functionalization of $\mathrm{ZnO}$ nanoparticles by N-(trimethoxysilylpropyl) ethylenediamine triacetic acid (TMSEDTA): Investigation of the interactions between Phloroglucinol and ZnO@ TMSEDTA, Arabian Journal of Chemistry, 2019, 12: 4340-4347.

[65] R.M. Tripathi, S.J. Chung, Phytosynthesis of Palladium Nanoclusters: An Efficient Nanozyme for Ultrasensitive and Selective Detection of Reactive Oxygen Species, Molecules, 2020, 25: 3349.

[66] M. Mansha, A. Qurashi, N. Ullah, et al., Synthesis of $\mathrm{In}_{2} \mathrm{O}_{3}$ /graphene heterostructure and their hydrogen gas sensing properties, Ceramics International, 2016, 42: 11490-11495.

[67] M. Ganesh, P. Hemalatha, M.M. Peng, et al., One pot synthesized $\mathrm{Li}, \mathrm{Zr}$ doped porous silica nanoparticle for low temperature $\mathrm{CO}_{2}$ adsorption, Arabian Journal of Chemistry, 2017, 10: 1501-1505.

[68] M. Shaalan, M. Saleh, M. El-Mahdy, et al., Recent progress in applications of nanoparticles in fish medicine: a review, Nanomedicine: Nanotechnology, Biology and Medicine, 2016, 12: 701-710.

[69] D. Vollath, W.V.V.G. KGaA, Co, An introduction to synthesis, properties and application, Environmental Engineering and Management, 2008, 7: 865-870.

[70] Y. Sun, Y. Xia, Shape-controlled synthesis of gold and silver nanoparticles, Science, 2002, 298: 2176-2179.

[71] O. Kamigaito, What can be improved by nanometer composites? Journal of the Japan Society of Powder and Powder Metallurgy, 1991, 38: 315-321.

[72] A. Kelly, Concise encyclopedia of composite materials, Elsevier, 2012: 17-25.

[73] L.S. Schadler, Polymer-based and polymer-filled nanocomposites, Nanocomposite Science and Technology, 2003: 77-153.

[74] Z. Tian, H. Hu, and Y. Sun, A molecular dynamics study of effective thermal conductivity in nanocomposites, International Journal of heat and mass transfer, 2013, 61: $577-582$.

[75] F.E. Kruis, H. Fissan, and A. Peled, Synthesis of nanoparticles in the gas phase for electronic, optical and magnetic applications - a review, Journal of Aerosol Science, 1998, 29: 511-535.

[76] S. Zhang, D. Sun, Y. Fu, et al., Recent advances of superhard nanocomposite coatings: a review, Surface and Coatings Technology, 2003, 167: 113-119.

[77] D. Janas, B. Liszka, Copper matrix nanocomposites based on carbon nanotubes or graphene, Materials Chemistry Frontiers, 2018, 2: 22-35.

[78] E. Manias, Stiffer by design, Nature Materials, 2007, 6:
9-11.

[79] S. Kim, S.J. Hwang, and W. Choi, Visible light active platinum-ion-doped $\mathrm{TiO}_{2}$ photocatalyst, The Journal of Physical Chemistry B, 2005, 109: 24260-24267.

[80] Y. Cao, W. Yang, W. Zhang, et al., Improved photocatalytic activity of $\mathrm{Sn}^{4+}$ doped $\mathrm{TiO}_{2}$ nanoparticulate films prepared by plasma-enhanced chemical vapor deposition, New Journal of Chemistry, 2004, 28: 218-222.

[81] W. Choi, A. Termin, and M.R. Hoffmann, The role of metal ion dopants in quantum-sized $\mathrm{TiO}_{2}$ : correlation between photoreactivity and charge carrier recombination dynamics, The Journal of Physical Chemistry, 2002, 98: 13669-13679.

[82] W. Choi, A. Termin, and M.R. Hoffmann, Effects of metal-ion dopants on the photocatalytic reactivity of quantum-sized $\mathrm{TiO}_{2}$ particles, Angewandte Chemie International Edition in English, 1994, 33: 1091-1092.

[83] S. Behrens, I. Appel, Magnetic nanocomposites, Current Opinion in Biotechnology, 2016, 39: 89-96.

[84] M. Jacinto, L. Ferreira, and V. Silva, Magnetic materials for photocatalytic applications-a review, J Sol-Gel Sci Technol, 2020, 96: 1-14.

[85] C.H. Wu, C.L. Chang, Decolorization of Reactive Red 2 by advanced oxidation processes: Comparative studies of homogeneous and heterogeneous systems, Journal of Hazardous Materials, 2006, 128: 265-272.

[86] I.T. Peternel, N. Koprivanac, A.M.L. Božić, et al., Comparative study of $\mathrm{UV} / \mathrm{TiO}_{2}, \mathrm{UV} / \mathrm{ZnO}$ and photoFenton processes for the organic reactive dye degradation in aqueous solution, Journal of Hazardous Materials, 2007, 148: 477-484.

[87] A.L. Linsebigler, G. Lu, and J.T. Yates Jr, Photocatalysis on $\mathrm{TiO}_{2}$ surfaces: Principles, mechanisms, and selected results, Chemical Reviews, 1995, 95: 735-758.

[88] N. Daneshvar, D. Salari, and A. Khataee, Photocatalytic degradation of azo dye acid red 14 in water on $\mathrm{ZnO}$ as an alternative catalyst to $\mathrm{TiO}_{2}$, Journal of Photochemistry and Photobiology A: Chemistry, 2004, 162: 317-322.

[89] K.M. Lee, C.W. Lai, K.S. Ngai, et al., Recent developments of zinc oxide based photocatalyst in water treatment technology: A review, Water Research, 2016, 88: 428-448.

[90] Z. Ye, L. Kong, F. Chen, et al., A comparative study of photocatalytic activity of $\mathrm{ZnS}$ photocatalyst for degradation of various dyes, Optik, 2018, 164: 345-354.

[91] R. Saravanan, F. Gracia, and A. Stephen, Basic principles, mechanism, and challenges of photocatalysis, nanocomposites for visible light-induced photocatalysis, Springer, 2017: 19-40.

[92] A.A. Isari, A. Payan, M. Fattahi, et al., Photocatalytic degradation of rhodamine $\mathrm{B}$ and real textile wastewater using $\mathrm{Fe}$-doped $\mathrm{TiO}_{2}$ anchored on reduced graphene oxide $\left(\mathrm{Fe}-\mathrm{TiO}_{2} / \mathrm{rGO}\right)$ : characterization and feasibility, mechanism and pathway studies, Applied Surface Science, 2018, 462: 549-564.

[93] A. Khataee, M.B. Kasiri, Photocatalytic degradation of organic dyes in the presence of nanostructured titanium dioxide: Influence of the chemical structure of dyes, Journal of Molecular Catalysis A: Chemical, 2010, 328: 8-26.

[94] S. Jorfi, S. Mirali, A. Mostoufi, et al., Visible light photocatalytic degradation of azo dye and a real textile wastewater using $\mathrm{Mn}, \mathrm{Mo}, \mathrm{La} / \mathrm{TiO}_{2} / \mathrm{AC}$ nanocomposite, Chemical and Biochemical Engineering Quarterly, 2018, 32: 215-227.

[95] H.D. Burrows, J. Santaballa, and S. Steenken, Reaction pathways and mechanisms of photodegradation of pesticides, Journal of Photochemistry and Photobiology B: Biology, 2002, 67: 71-108.

[96] M.N. Chong, B. Jin, C.W. Chow, et al., Recent 
developments in photocatalytic water treatment technology: a review, Water Research, 2010, 44: 2997 3027.

[97] Z, Yangyang, Modeling and Design of Photocatalytic reactors for Air Purification, Graduate Theses and Dissertations, Florida, USA, 2013.

[98] S. Leong, A. Razmjou, K. Wang, et al., $\mathrm{TiO}_{2}$ based photocatalytic membranes: A review, Journal of Membrane Science, 2014, 472: 167-184.

[99] F. Silva, M. Lansarin, and C. Moro, A comparison of slurry and inmobilized $\mathrm{TiO}_{2}$ in the photocatalytic degradation of phenol, Latin American Applied Research, 2012, 42: 275-280.

[100] L. Yu, Light emitting diode based photochemical treatment of contaminants in aqueous phase, Unpublished doctoral thesis, University of Calgary, Calgary, AB, 2014.

[101] W. Zhang, L. Ding, J. Luo, et al., Membrane fouling in photocatalytic membrane reactors (PMRs) for water and wastewater treatment: A critical review, Chemical Engineering Journal, 2016, 302: 446-458.

[102] A. Fernández-García, E. Zarza, L. Valenzuela, et al., Parabolic-trough solar collectors and their applications, Renewable and Sustainable Energy Reviews, 2010, 14: 1695-1721.

[103] J. Blanco-Galvez, P. Fernández-Ibáñez, and S. MalatoRodríguez, Solar photocatalytic detoxification and disinfection of water: recent overview, 2007.

[104] D. Spasiano, R. Marotta, S. Malato, et al., Solar photocatalysis: materials, reactors, some commercial, and pre-industrialized applications. A comprehensive approach, Applied Catalysis B: Environmental, 2015, 170: 90-123.

[105] D.N. Priya, J.M. Modak, and A.M. Raichur, LbL fabricated poly (styrene sulfonate) $/ \mathrm{TiO}_{2}$ multilayer thin films for environmental applications, ACS Applied Materials \& Interfaces, 2009, 1: 2684-2693.

[106] I. Ali, M. Asim, and T.A. Khan, Low cost adsorbents for the removal of organic pollutants from wastewater, Journal of Environmental Management, 2012, 113: 170183.

[107] W.T. Tsai, H.C. Hsu, T.Y. Su, et al., The adsorption of cationic dye from aqueous solution onto acid-activated andesite, Journal of Hazardous Materials, 2007, 147: 1056-1062.

[108] C. Wang, J. Zhang, P. Wang, et al., Adsorption of methylene blue and methyl violet by camellia seed powder: kinetic and thermodynamic studies, Desalination and Water Treatment, 2015, 53: 3681-3690.

[109] S. Allen, B. Koumanova. Decolourisation of water/ wastewater using adsorption, Journal of University of Chemical Technology and Metallurgy, 2005, 40: 175-192.

[110] D. Wang, T. Silbaugh, R. Pfeffer, et al., Removal of emulsified oil from water by inverse fluidization of hydrophobic aerogels, Powder Technology, 2010, 203: 298-309.

[111] D. Lin, Q. Zhao, L. Hu, et al., Synthesis and characterization of cubic mesoporous bridged polysilsesquioxane for removing organic pollutants from water, Chemosphere, 2014, 103: 188-196.

[112] W. Nam, J.H. Park, and G.Y. Han, Enhanced photocatalytic oxidation properties in $\mathrm{Pt}-\mathrm{TiO}_{2}$ thin films by grounding, Korean Journal of Chemical Engineering, 2009, 26: 392-397.

[113] P. Wang, T. Zhou, R. Wang, et al., Carbon-sensitized and nitrogen-doped $\mathrm{TiO}_{2}$ for photocatalytic degradation of sulfanilamide under visible-light irradiation, Water Research, 2011, 45: 5015-5026.

[114] L. Ritter, K. Solomon, J. Forget, et al., A review of selected persistent organic pollutants, International Programme on Chemical Safety (IPCS). PCS/95.39.
Geneva: World Health Organization, 1995, 65-66.

[115] M. El-Shahawi, A. Hamza, A. Bashammakh, et al., An overview on the accumulation, distribution, transformations, toxicity and analytical methods for the monitoring of persistent organic pollutants, Talanta, 2010, 80: 1587-1597.

[116] T. Nkambule, R. Krause, B. Mamba, et al., Removal of natural organic matter from water using ion-exchange resins and cyclodextrin polyurethanes, Physics and Chemistry of the Earth, Parts A/B/C, 2009, 34: 812-818.

[117] V. Kanokkantapong, T.F. Marhaba, P. Pavasant, et al., Characterization of haloacetic acid precursors in source water, Journal of Environmental Management, 2006, 80: 214-221.

[118] F.H. Frimmel, G. Abbt-Braun, K.G. Heumann, et al., Refractory Organic Substances in the Environment, John Wiley \& Sons, 2008.

[119] C. Zhang, M. Meier, A. Lambertz, et al., Optical and electrical effects of p-type $\mu c-\mathrm{SiO}_{x}: \mathrm{H}$ in thin-film silicon solar cells on various front textures, International Journal of Photoenergy, 2014, 2014: 1-10.

[120] M. Delay, H. Schwegmann, and F.H. Frimmel, Nanoparticles and refractory organic matter: interactions and consequences, Journal of Environmental Chemical Engineering, 2015, 3: 2997-3004.

[121] C.C. Wang, J.R. Li, X.L. Lv, et al., Photocatalytic organic pollutants degradation in metal-organic frameworks, Energy \& Environmental Science, 2014, 7: 2831-2867.

[122] J. Zhao, C. Chen, and W. Ma, Photocatalytic degradation of organic pollutants under visible light irradiation, Topics in Catalysis, 2005, 35: 269-278.

[123] K. Wu, Y. Xie, J. Zhao, et al., Photo-Fenton degradation of a dye under visible light irradiation, Journal of Molecular Catalysis A: Chemical, 1999, 144: 77-84.

[124] F. Chen, J. He, J. Zhao, et al., Photo-Fenton degradation of malachite green catalyzed by aromatic compounds under visible light irradiation, New Journal of Chemistry, 2002, 26: 336-341.

[125] A. Fujishima, T.N. Rao, and D.A. Tryk, Titanium dioxide photocatalysis, Journal of Photochemistry and Photobiology C: Photochemistry Reviews, 2000, 1: 1-21.

[126] D.M. Blake, Bibliography of Work on the Heterogeneous Photocatalytic Removal of Hazardous Compounds from Water, National Renewable Energy Lab., Golden, CO (US), 1999.

[127] O. Legrini, E. Oliveros, and A. Braun, Photochemical processes for water treatment, Chemical Reviews, 1993, 93: 671-698.

[128] S.K. Maji, A.K. Dutta, D.N. Srivastava, et al., Effective photocatalytic degradation of organic pollutant by $\mathrm{ZnS}$ nanocrystals synthesized via thermal decomposition of single-source precursor, Polyhedron, 2011, 30: 24932498.

[129] T.J. Whang, H.Y. Huang, M.T. Hsieh, et al., Laser-induced silver nanoparticles on titanium oxide for photocatalytic degradation of methylene blue, International Journal of Molecular Sciences, 2009, 10: 4707-4718.

[130] J. Zhao, X. Yang, Photocatalytic oxidation for indoor air purification: A literature review, Building and Environment, 2003, 38: 645-654.

[131] D. Das, N. Biswal, S. Martha, et al., Solar-light induced photodegradation of organic pollutants over CdSpillared zirconium-titanium phosphate (ZTP), Journal of Molecular Catalysis A: Chemical, 2011, 349: 36-41.

[132] N. Soltani, E. Saion, M.Z. Hussein, et al., Visible lightinduced degradation of methylene blue in the presence of photocatalytic $\mathrm{ZnS}$ and $\mathrm{CdS}$ nanoparticles, International Journal of Molecular Sciences, 2012, 13: 12242-12258.

[133] X. Xu, R. Lu, X. Zhao, et al., Fabrication and photocatalytic performance of a $\mathrm{ZnxCd1-xS}$ solid solution 
prepared by sulfuration of a single layered double hydroxide precursor, Applied Catalysis B: Environmental, 2011, 102: 147-156.

[134] S. Liu, H. Li, and L. Yan, Synthesis and photocatalytic activity of three-dimensional $\mathrm{ZnS} / \mathrm{CdS}$ composites, Materials Research Bulletin, 2013, 48: 3328-3334.

[135] L. Cheng, Q. Xiang, Y. Liao, et al., CdS-based photocatalysts, Energy \& Environmental Science, 2018, 11: 1362-1391.

[136] S.P. Bhaskar, M.S. Karthika, and B.R. Jagirdar, Au/CdS nanocomposite through digestive ripening of $\mathrm{Au}$ and $\mathrm{CdS}$ nanoparticles and its photocatalytic activity, Chemistry Select, 2018, 3: 6638-6646.

[137] S. Pan, X. Liu, CdS-Graphene nanocomposite: synthesis, adsorption kinetics and high photocatalytic performance under visible light irradiation, New Journal of Chemistry, 2012, 36: 1781-1787.

[138] M. Mahanthappa, N. Kottam, and S. Yellappa, Enhanced photocatalytic degradation of methylene blue dye using CuSCdS nanocomposite under visible light irradiation, Applied Surface Science, 2109, 475: 828-838.

[139] R. Rajendran, K. Varadharajan, V. Jayaraman, et al., Photocatalytic degradation of metronidazole and methylene blue by PVA-assisted $\mathrm{Bi}_{2} \mathrm{WO}_{6}-\mathrm{CdS}$ nanocomposite film under visible light irradiation, Applied Nanoscience, 2018, 8: 61-78.

[140] R. Moqbel, M. Gondal, T. Qahtan, et al., Photocatalytic application of CdS nanoparticles and CdS/RGO hybrid composite synthesized by pulsed laser ablation method, Proceedings of AIP Conference, AIP Publishing LLC, 2018: 020015.
[141] S.S. Srinivasan, J. Wade, and E.K. Stefanakos, Visible light photocatalysis via $\mathrm{CdS} / \mathrm{TiO}_{2}$ nanocomposite materials, Journal of Nanomaterials, 2006, 2006: 1-7.

[142] P. Chaengchawi, K. Serivalsatit, and P. Sujaridworakun, Synthesis of visible-light responsive $\mathrm{CdS} / \mathrm{ZnO}$ nanocomposite photocatalysts via simple precipitation method, Key Engineering Materials, 2014, 608: 224-229.

[143] Y. Qiu, Z. Ma, and P. Hu, Environmentally benign magnetic chitosan/ $/ \mathrm{Fe}_{3} \mathrm{O}_{4}$ composites as reductant and stabilizer for anchoring $\mathrm{Au}$ NPs and their catalytic reduction of 4-nitrophenol, Journal of Materials Chemistry A, 2014, 2: 13471-13478.

[144] D. Wu, F. Wang, Y. Tan, et al., Facile synthesis of NiS/ $\mathrm{CdS}$ nanocomposites for photocatalytic degradation of quinoline under visible-light irradiation, RSC Advances, 2016, 6: 73522-73526.

[145] D. Prabha, K. Usharani, S. Ilangovan, et al., Visible light irradiated photocatalytic activity of $\mathrm{SnS}_{2}-\mathrm{CdS}$ nanocomposite against the degradation of methyl orange dye, Materials Technology, 2018, 33: 333-339.

[146] C. Lin, Y. Song, L. Cao, et al., $\mathrm{TiO}_{2}$ nanotubes/ $\mathrm{ZnO} / \mathrm{CdS}$ ternary nanocomposites: preparation, characterization and photocatalysis, Journal of the Chinese Advanced Materials Society, 2103, 1: 188-199.

Copyright $(\subset$ Sanya Mishra, Ravi Mani Tripathi, and Om Prakash Sinha. This is an open-access article distributed under the terms of the Creative Commons Attribution License, which permits unrestricted use, distribution, and reproduction in any medium, provided the original author and source are credited. 